\title{
A práxis antitruste no Brasil: uma análise do CADE no período 1994-2004¹
}

\author{
Marina Moreira da Gama \\ Ricardo Machado Ruiz ${ }^{3}$
}

\section{Resumo}

A política de defesa da concorrência é construída através das decisões dos órgãos antitruste nacionais que, no caso brasileiro, são proferidas pelo CADE. Avaliar as decisões do CADE é, portanto, avaliar a defesa da concorrência no Brasil. Um modo de avaliar a práxis antitruste brasileira consiste em observar se as decisões do CADE estão de acordo com as convencionais teorias utilizadas na análise antitruste. O objetivo deste trabalho é, portanto, analisar a consistência teórica dos julgados do CADE. Para tanto, são avaliados 330 votos de Conselheiros-Relatores no período de vigência da Lei $8.884 / 94$, ou entre 1994 e 2004. A conclusão do estudo é que há uma generalizada fragilidade na aplicação da teoria antitruste pelo CADE.

Palavras-chave: Antitruste; Mercado relevante; Poder de mercado; CADE; Brasil.

\section{Abstract \\ The antitrust policy in Brazil: an analysis of CADE (1994-2004)}

The antitrust policy is built through antitrust agency's decisions that are, in Brazil, pronounced by CADE. To appraise CADE's decisions, thus, is to appraise the antitrust policy in Brazil. This implies that is necessary to know if such decisions are consistent with the antitrust theory. The purpose of this paper is to verify the theoretical consistency of CADE's decisions. To get there, 330 Counsel's votes are analyzed on the legality lifetime of the 8.884/94 Law, between 1994 and 2004. The paper's conclusion is that there is a general fragility in antitrust theory's application by CADE.

Key words: Antitrust; Relevant market; Market power; CADE.

JEL L40, L44, K21.

\section{Introdução}

A política de defesa da concorrência é construída através das decisões dos órgãos antitruste nacionais que, no caso brasileiro, são proferidas pelo CADE (Conselho Administrativo de Defesa Econômica). Avaliar as decisões do CADE é, portanto, avaliar como a defesa da concorrência é feita no Brasil. Um modo de

(1) Trabalho recebido em março de 2006 e aprovado em junho de 2006.

(2) Doutoranda em Economia pelo Centro de Desenvolvimento e Planejamento Regional (Cedeplar) da Universidade Federal de Minas Gerais (UFMG) e bolsista da Fundação de Amparo à Pesquisa do Estado de Minas Gerais (Fapemig). E-mail: mgama@cedeplar.ufmg.br

(3) Professor Adjunto da Faculdade de Ciências Econômicas (FACE) da UFMG e Cedeplar/UFMG. Bolsista em Produtividade e Pesquisa do Conselho Nacional de Desenvolvimento Científico e Tecnológico (CNPq). E-mail: rmruiz@cedeplar.ufmg.br 
avaliar a práxis antitruste brasileira consiste em observar se as decisões do CADE estão de acordo com as convencionais teorias utilizadas na análise antitruste. $\mathrm{O}$ objetivo deste trabalho é, portanto, analisar a consistência teórica dos casos julgados do CADE no período de vigência da Lei 8.884/94, ou entre 1994 e 2004, pois é a partir daí que se definem a práxis política dessa autarquia e sua relevância como instituição que se propõe reguladora da estrutura produtiva brasileira. Do ponto de vista econômico, avaliar a consistência teórica das decisões do CADE significa verificar se a teoria econômica utilizada como referência - aqui denominada de teoria antitruste - está sendo rigorosamente utilizada por essa instituição.

Para tanto, este trabalho se divide em cinco seções, incluindo esta introdução. A primeira seção traz as referências teóricas da política antitruste. A segunda descreve essa teoria e seus procedimentos para avaliação de atos de concentração e práticas restritivas, tais como a delimitação do mercado relevante, a possibilidade de exercício de poder de mercado e a avaliação das eficiências econômicas líquidas. A terceira seção trata da metodologia de avaliação dos casos julgados pelo CADE. A quarta apresenta os resultados consolidados da análise sobre essa autarquia federal. E a última parte faz as considerações gerais sobre a práxis antitruste no Brasil.

\section{Referências teóricas da política antitruste}

Como muitas das legislações positivas, as leis sobre a defesa da concorrência, ou antitruste, como preferem alguns especialistas, antecederam a teoria econômica que lhes confere sustentação. Isto é, a lei antecipou a teoria econômica acerca da matéria antitruste. Historicamente, a legislação antitruste, na sua forma mais moderna, é uma "invenção" da América do Norte. O Canadá aprovou um estatuto antitruste em 1889; os Estados Unidos adotaram o Sherman Act em 1890. Essas leis representaram uma reação política à turbulenta mudança econômica do final do século XIX que produziu indústrias extremamente concentradas e, muitas vezes, cartelizadas (Scherer; Ross, 1990; Viscusi et al., 1995 e Gama, 2005a).

Já considerando a evolução teórica da política antitruste, é possível dizer que a defesa da concorrência teve origem nas teorias de Organização Industrial que constituíram o chamado modelo Estrutura-Conduta-Desempenho (ECD), tal como foi divulgado a partir dos anos 1950 pela chamada "Escola de Harvard". Esse modelo deriva das características das configurações do mercado conclusões sobre a sua performance, supondo para isso que as condutas das empresas são condicionadas pela estrutura. As políticas antitruste elaboradas estritamente a 
partir dessa abordagem vão se preocupar, sobretudo, com o aumento da concentração do mercado e com a presença de barreiras à entrada.

Considera-se que em um mercado concentrado (estrutura), no qual as empresas têm poder de decidir o preço cobrado, este e as margens de lucro serão maiores (desempenho), porque as empresas apresentam elevado grau de coordenação (conduta). Isto é, a estrutura influencia a conduta e determina o desempenho. Ainda para essa análise estruturalista, quanto maiores as barreiras à entrada, maior a possibilidade de colusão e elevação dos preços e melhor o desempenho das firmas em termos de lucratividade. Consoante Bain (1956), o principal fator estrutural que afeta a conduta colusiva das empresas já estabelecidas é a concentração, já que a coordenação entre firmas ocorre mais facilmente quando seu número é reduzido no mercado em análise. Esse entendimento estruturalista, segundo Possas (1985, p. 95), consiste em "tomar a concentração econômica como elemento básico da estrutura [de mercado] e a intensidade das barreiras à entrada como indicador-chave do poder de mercado das empresas oligopolistas...”.

O problema dessa visão, salientado por seus principais críticos, os teóricos da dita "Escola de Chicago", é que a concentração não deve ser a variável principal e decisiva a ser considerada na análise antitruste. Isso porque, por um lado, concentração reflete apenas o número de concorrentes em um mercado e a desigualdade de tamanho entre eles, não havendo razão para supor que os comportamentos dos agentes serão simétricos e colusivos (Tirole, 2002). Quanto à avaliação empírica, os testes econométricos realizados entre concentração e variáveis que refletem o desempenho da firma, como lucratividade, margem de lucro e markup, são inconclusivos, inclusive quando tratam da direção da causalidade. $^{4}$

Assim, não mais se sustenta que a concentração seja uma indicação segura para a conduta dos competidores e por isso a justificativa para intervenção governamental via aplicação de legislação antitruste. Em poucas palavras, "a concentração industrial é uma condição necessária para a acumulação assimétrica de poder de mercado, e por consequiência para a possibilidade de seu exercício de forma anticompetitiva; mas de modo algum é condição suficiente" (Possas, 1996, p. 21).

A "Escola de Chicago" rompe, assim, com a tradição essencialmente estruturalista da teoria antitruste ao considerar que a concentração em si não é um mal, desde que seja vista em termos da eficiência econômica (produção ao menor custo). Estruturas concentradas, se resultarem em uma economia de recursos que compense seus efeitos anticompetitivos, não podem ser consideradas ineficientes.

(4) Ver a resenha de Geroski (1988). 
Essa visão propõe a análise do efeito líquido resultante da comparação entre os ganhos de eficiência gerados e as possíveis ou reais perdas decorrentes de efeitos anticompetitivos (Salgado, 1997).

Em suma, a atual teoria antitruste foi construída tendo com referência essas duas escolas. A visão estruturalista sofreu uma modificação fundamental em decorrência da maior preocupação em considerar as eficiências econômicas, sobretudo as de caráter produtivo (redução de custos via economias de escala e escopo), que podem contrabalançar a presença de estruturas de mercado mais concentradas e determinadas condutas empresariais. Como resultado, os órgãos de defesa da concorrência em diversos países tendem a avaliar não somente os efeitos anticompetitivos na estrutura de mercado (aumento da concentração), como na tradição ECD, mas também os potenciais impactos em termos de ganhos de eficiência. De um ponto de vista conceitual, toda e qualquer análise antitruste de ato ou conduta que gere algum efeito anticompetitivo envolve, como passo conclusivo, a avaliação dos efeitos líquidos em termos de eficiência do ato ou conduta examinado.

\section{A teoria antitruste e o roteiro de avaliação}

A análise antitruste parte da possibilidade de exercício de poder de mercado. Um ato de concentração ou uma conduta de uma firma só será considerado anticompetitivo se resultar em criação ou aumento de poder de mercado, compreendido como a capacidade da empresa em manter preços acima do nível competitivo por um determinado período de tempo.

Para que seja constatado que houve exercício de poder de mercado, a teoria antitruste faz a análise do caso seguindo um roteiro de avaliação que padroniza e, dessa forma, agiliza o trâmite dos processos (Oliveira; Rodas, 2004). Assim, ela se vale de três passos básicos seqüenciais: (i) a conceituação de mercado relevante; (ii) a análise das condições de exercício de poder de mercado; (iii) o exame das eficiências geradas pela operação. A partir dessas considerações, o ato ou conduta será aprovado ou condenado. Esse roteiro tem como base a teoria antitruste convencional $^{5}$ e é utilizado pelos órgãos de defesa da concorrência para avaliar atos de concentração e práticas restritivas, dadas as peculiaridades tanto de atos quanto de condutas. ${ }^{6}$ Por isso, esse roteiro será a referência para a análise da práxis da defesa da concorrência no Brasil.

(5) O que chamamos de teoria antitruste convencional são conceitos de Organização Industrial encontrados nos guias para análise de atos de concentração e práticas restritivas estadunidense, europeu e brasileiro.

(6) A avaliação de ato de concentração difere da avaliação de prática restritiva, mas em ambas há um core comum, isto é, a necessidade de delimitação de mercado relevante, avaliação do exercício de poder de mercado e análise da eficiência econômica, por isso a possibilidade do estudo em conjunto. 


\subsection{O conceito de mercado relevante}

O mercado relevante, conceito rotineiramente utilizado na análise antitruste, é definido como o menor espaço econômico, em termos de produto, e geográfico, no qual o poder de mercado é possível de ser exercido por uma firma atuando de forma isolada ou grupo de empresas agindo de forma coordenada, durante um certo período de tempo (Hovenkamp, 1994; Scherer; Ross, 1990; Carlton; Perloff, 2000). Portanto, a delimitação do mercado relevante deve ser feita considerando-se a substituibilidade da demanda nas suas três dimensões: a do produto, a geográfica e a temporal, além da substituibilidade da oferta.

\subsubsection{A substitutibilidade da demanda}

A substituibilidade da demanda considera a permuta entre produtos do ponto de vista do consumidor e possui três dimensões. Na dimensão do produto, a questão essencial é saber como muda o consumo de um produto a partir de mudanças no seu preço relativo. Por exemplo, se o preço do produto A aumentar em um percentual pequeno e significativo e, como resultado, os consumidores substituírem o produto A pelo produto B em quantidades relevantes, então A e B são bens substitutos e poderão, segundo essa dimensão, ser incluídos no mesmo mercado.

Para determinar a extensão do mercado relevante em termos do produto, três testes (métodos) têm sido utilizados de forma recorrente (Scherer; Ross, 1990), embora não haja sua obrigatoriedade. O primeiro teste consiste em estimar as elasticidades-preço cruzadas da demanda, que medem o percentual de mudança na quantidade demandada de um bem em resposta ao aumento de um ponto percentual no preço de outro bem. O segundo teste está baseado na suposição de que se dois produtos estão no mesmo mercado, então a variação de seus preços ao longo do tempo deverá ocorrer na mesma direção e em percentuais muito próximos (Price correlation over time). Se o coeficiente de correlação calculado entre os preços de dois produtos for relativamente alto, presume-se que esses produtos estejam no mesmo mercado. Por fim, o terceiro teste é o Teste do Monopolista Hipotético (TMH) proposto pelo Guia de Fusões Horizontais NorteAmericano (Guidelines, 1997), ${ }^{7}$ que analisa a possível resposta dos consumidores diante de um aumento de preços de um certo produto, normalmente convencionado em $5 \%$, mas ampliável para $10 \%$ ou $15 \%$, durante um ano, realizado por um monopolista hipotético naquele mercado. ${ }^{8}$ Aqui também é fundamental o conceito de elasticidade-preço da demanda, sobretudo quando não houver produtos substitutos para delimitar o mercado relevante.

(7) Horizontal Merger Guidelines (1997), dos EUA.

(8) Para melhor definição dos testes, ver Gama (2005a) e Scherer e Ross (1990). 
A segunda dimensão da demanda a ser analisada na delimitação do mercado relevante é a geográfica. Há também a possibilidade de utilização do TMH ao se considerar que o aumento de preços de uma região afeta substancialmente o preço em outra região. Nesse caso, ambas as regiões fariam parte do mercado. Esse processo deve ser repetido até que se conclua que os ofertantes da última área delimitada tomam suas decisões de política de preços sem se preocupar com os ofertantes da nova área proposta. O mercado relevante pode ser regional, nacional e até mesmo internacional.

A terceira dimensão a ser destacada na definição de mercado relevante é a dimensão temporal da substituição, que incide sobre as outras duas dimensões, a de produtos e a geográfica. Quanto maior for o lapso de tempo considerado para avaliar a reação da oferta e da procura, maior será a amplitude do mercado delimitado, e vice-versa. Cabe notar, no entanto, que, se por um lado, uma redução exagerada da dimensão temporal impede que se incorporem ofertantes potenciais, por outro, a sua ampliação desmesurada limita a capacidade de intervenção da agência reguladora. Convencionalmente, o período de tempo é próximo a um ano, podendo ser ampliado ou reduzido de acordo com as especificações do mercado.

\subsubsection{Substitutibilidade da oferta}

Completada a delimitação do mercado relevante pelo lado da demanda, a substituibilidade do produto pelo lado da oferta também deve ser considerada para efeito de identificação dos participantes desse mercado. Isso é feito pela inclusão, no mercado relevante já definido em termos de produto, geográfico e temporal, dos ofertantes potenciais desse produto que podem fazê-lo com relativa facilidade, isto é, a baixo custo adicional e prazo relativamente curto, por já disporem de capacidade produtiva instalada, que pode ser remanejada para a produção para o mercado em questão.

Segundo Salgado (1997, p. 53), “a flexibilidade na oferta é importante para identificar os produtores que podem vir a ofertar para um determinado mercado previamente delimitado, diante de oportunidades de realização de lucro extraordinário". Isto é, a capacidade produtiva já instalada, que poderá ser utilizável de forma suficientemente ágil na produção dos produtos definidos como pertencentes ao mercado relevante, gerando assim uma oferta potencial suficientemente elástica dos mesmos, deve ser computada no cálculo da oferta e na delimitação dos participantes do mercado relevante (Possas, 1996). São os chamados uncommitted entrants, na terminologia do Guidelines (1997), porque sua entrada no mercado não requer investimentos significativos em custos irrecuperáveis (sunk costs). 


\subsection{As condições de exercício de poder de mercado}

Uma vez delimitado o mercado relevante, a utilização de medidas de concentração de mercado, a análise da competição externa e a avaliação do nível das barreiras à entrada são os principais instrumentos de inferência da extensão do poder de mercado naquele mercado relevante concreto utilizados pela teoria antitruste.

\subsection{1 Índices de concentração de mercado}

Seguindo as proposições do enfoque estruturalista de Organização Industrial, há a crença de que uma operação de concentração gera poder de mercado. Há dois tipos de índices mais comumente utilizados ${ }^{9}$ : os índices de participação das maiores empresas do mercado (Ci), e o índice de Herfindhal Hirschman (HHI). ${ }^{10}$

Os critérios para identificar se a concentração gera um controle sobre parcela relevante do mercado são diferentes entre os países. O SBDC (Sistema Brasileiro de Defesa da Concorrência) considera uma participação igual ou superior a $20 \%$ do mercado relevante como um ponto crítico (artigo $20, \S 2^{\circ}$, da Lei n. 8.884/94). Para o Guia Brasileiro (Guia, 2001 ${ }^{11}$ ), uma concentração viabiliza o exercício de poder de mercado sempre que: (i) a concentração tornar a soma da participação de mercado das quatro maiores empresas (C4) igual ou superior a $75 \%$, e (ii) a participação da nova empresa formada for igual ou superior a $10 \%$ do mercado relevante. Quanto ao HHI, o critério utilizado é o Guidelines (1997). O Quadro 1 sumariza esses convencionais procedimentos.

Quadro 1

Variações no Índice de Concentração HH

\begin{tabular}{|l|c|c|c|}
\hline \multirow{2}{*}{} & \multicolumn{2}{|l|}{ Variações de Pontos do HHI $-X$} \\
\cline { 2 - 4 } & $\mathrm{X}<50$ & $50<\mathrm{X}<100$ & $\mathrm{X}>100$ \\
\hline $\mathrm{HHI}>1800$ & Região Segura & Região de Alerta & Região de Alerta \\
\hline $1000<\mathrm{HHI}<1800$ & Região Segura & Região Segura & Região de Alerta \\
\hline $\mathrm{HHI}<1000$ & Região Segura & Região Segura & Região Segura \\
\hline
\end{tabular}

Fonte: Viscusi et al. (1995).

(9) Existem outros índices para medir concentração de mercado. Ver Kupfer e Hasenclever (2002).

(10) Os índices "Ci”" medem a participação percentual das "i" maiores empresas no mercado relevante, e o HHI corresponde ao somatório dos quadrados das participações de todas as empresas no mercado ou HHI $=\Sigma$ si2.

(11) Ver Guia para Análise Econômica de Atos de Concentração Horizontal (2001) da SEAE (Secretaria de Acompanhamento Econômico) e da SDE (Secretaria de Direito Econômico). 


\subsubsection{Viabilidade da competição externa}

A possibilidade de aquisição de um bem através da importação, mesmo que ainda não esteja efetivamente ocorrendo, é um dos determinantes da concorrência no mercado doméstico e, conseqüentemente, um fator capaz de inibir o exercício do poder de mercado (Guia, 2001). Sendo assim, se a concentração ocorrer em um mercado cujas importações podem ser efetivadas, é pouco provável que um ato de concentração e/ou uma conduta anticompetitiva gerem problemas concorrenciais (Guia, 2001).

\subsubsection{Condições de entrada de novas firmas}

Uma análise das condições de entrada no mercado, em princípio independentemente do grau de concentração vigente, é fundamental, uma vez que uma entrada livre reduziria a necessidade de ação antitruste (Geroski, 1988). Em outras palavras, uma operação que aumente a concentração pode não criar nem reforçar poder de mercado se a concorrência potencial for vigorosa (Bonner; Krueger, 1991). Dessa maneira, para a teoria antitruste convencional, pode-se dizer que a concorrência potencial tem a mesma relevância que a concorrência efetiva (Hovenkamp, 1994).

Para o Guidelines (1997) e o Guia (2001), a entrada deve ser realizada (ou possível de ser realizada, quando da ameaça crível de entrada) por agentes comprometidos com a estratégia de entrada no mercado (os chamados committed entrants), ou seja, os potenciais entrantes devem ser capazes de enfrentar eventuais barreiras existentes, incorrendo inclusive em custos irrecuperáveis. Além disso, a entrada (ou sua ameaça crível) deve satisfazer as três condições descritas a seguir:

$1^{\text {a }}$ Condição: A entrada deve se realizar em um período de tempo de, aproximadamente, dois anos (timeliness of entry);

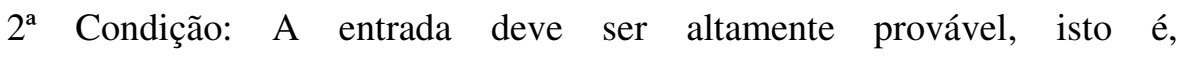
economicamente lucrativa a preços pré-concentração e quando esses preços puderem ser assegurados pelo possível entrante (likelihood of entry);

$3^{a}$ Condição: A entrada deve ser suficiente para trazer os preços para os patamares verificados antes da concentração ou conduta e permitir que todas as oportunidades de venda sejam adequadamente exploradas pelos entrantes em potencial (sufficiency of entry).

Satisfeitas as condições de entrada acima, o ato de concentração ou a prática restritiva são tidos como incapazes de ofender a concorrência, não gerando maiores preocupações da parte das autoridades da defesa da concorrência. 
Há um longo debate na teoria econômica sobre a natureza das barreiras à entrada. Bain (1956) considera as barreiras à entrada como um atributo da estrutura do mercado. Barreiras à entrada, ou as vantagens que as firmas estabelecidas têm sobre competidores potenciais e que se refletem na capacidade das mesmas em elevar persistentemente os preços acima dos níveis competitivos sem atrair novas firmas para o mercado em questão, são, assim, estruturais, estáveis e se modificam lentamente no tempo (Fagundes; Pondé, 1997). Segundo essa visão estruturalista do mercado, existem quatro tipos básicos de barreiras à entrada: Diferenciação de Produto, Vantagens Absolutas de Custo, Economias de Escala, Investimentos Iniciais Elevados.

As definições de Bain sobre barreiras à entrada foram criticadas, como toda a visão estruturalista da economia, pela "Escola de Chicago". Nesse contexto, Stigler (1968) argumentou que somente existem barreiras à entrada na presença de assimetrias entre as firmas estabelecidas e potenciais entrantes, ou seja, quando custos devem ser incorridos pelas entrantes, mas não pelas firmas instaladas. Para esse autor, economias de escala e elevados requisitos de capital, por exemplo, não devem ser considerados barreiras, na medida em que as firmas entrantes e as estabelecidas têm acesso às mesmas tecnologias e dispõem dos mesmos mercados de capitais para financiar seus investimentos. De um modo geral, a reavaliação das barreiras estruturais propostas por Bain foi feita à luz da noção de custos irrecuperáveis (sunk costs), custos com os quais uma empresa já estabelecida deve necessariamente arcar na hipótese de saída rápida do mercado (Viscusi et al., 1995). São, portanto, investimentos plenamente comprometidos (committed investments) com a entrada, cujos valores seriam inteiramente perdidos se não utilizados no mercado para o qual foram inicialmente destinados, ativos específicos na teoria dos custos de transação.

\subsection{A avaliação das eficiências}

O principal benefício propiciado por atos de concentração e/ou condutas anticompetitivas é o seu potencial de gerar ganhos de eficiência (melhoria da qualidade e menores preços). Assim, deve ser avaliado qual será o efeito líquido resultante da comparação entre os ganhos de eficiência gerados e as possíveis perdas decorrentes de efeitos anticompetitivos da operação (Scherer; Ross, 1990; Viscusi et al., 1995; Carlton; Perloff, 2000).

As eficiências consideradas pela análise antitruste são as produtivas e as relacionadas a reduções dos custos de transação. Eficiências produtivas são aquelas que resultam de economias reais de recursos que permanecem no longo prazo e permitem à firma aumentar a produção ou melhorar a qualidade dos produtos. A vantagem dessas eficiências é que podem ser comprovadas por 
documentos técnicos e contábeis (requisito legal). Já de acordo com a interpretação da teoria dos custos de transação, ${ }^{12}$ a especificidade de ativos, a incerteza e o oportunismo podem gerar ineficiências econômicas, assim o estabelecimento de vínculos de reciprocidade, as restrições contratuais às condutas das partes e as iniciativas de integração ou quase-integração ao longo das cadeias produtivas constituiriam, muitas vezes, formas organizacionais que geram ganhos de eficiência.

Para avaliar o efeito líquido resultante de um ato de concentração ou de uma conduta anticompetitiva, Willianson $(1968)^{13}$ propôs a análise do trade-off existente entre os ganhos de eficiência alocativa e os efeitos anticompetitivos do aumento de poder de mercado. Um ato ou conduta pode ser aprovado se o aumento do excedente do produtor em decorrência da redução de custos superar a perda de excedente do consumidor trazida pelo aumento de preços. ${ }^{14}$

O problema dessa abordagem é que ela desconsidera os efeitos sobre a distribuição de renda derivados do exercício do poder de mercado. Ao desconsiderar o efeito distributivo, o modelo de Willianson acaba por tornar indiferentes situações de concorrência perfeita e de monopólio com discriminação de preços perfeita, dado que em ambos os casos o excedente total é máximo, sendo apropriado inteiramente pelo consumidor, no primeiro caso, e pelo monopolista, no segundo caso. Assim, a consideração do excedente total como forma de avaliar o efeito líquido de um ato de concentração ou prática anticompetitiva, como faz Willianson, pode levar a uma situação injusta quanto à distribuição de renda entre produtores e consumidores (Possas, 2002).

Em consonância com um critério distributivo, a outra abordagem de mensuração das eficiências é denominada na literatura como 'padrão de preço' (Fisher et al., 1989). Nela, a aprovação de atos ou condutas depende, no mínimo, da manutenção do excedente do consumidor, ou seja, não pode haver aumento do preço do produto, mas somente redução de custos, levando a uma alocação ótima de Pareto. Para esse critério, as eficiências decorrentes de uma fusão, aquisição, associação ou conduta devem ser de tal magnitude que tornem inofensivo ao consumidor o poder de mercado implícito na operação.

A lei brasileira de defesa da concorrência prevê, no inciso II, parágrafo $1^{\circ}$ do artigo 54, que os "benefícios decorrentes sejam distribuídos eqüitativamente entre os seus participantes, de um lado, e os consumidores ou usuários finais, de outro". Desse modo, deveriam ser considerados na análise de casos brasileiros não

(12) Sobre essa teoria e sua relação com a defesa da concorrência, ver Possas et al. (1997).

(13) O artigo original de Willianson foi publicado em 1968, na American Economic Review, sendo posteriormente republicado algumas vezes com pequenas mudanças.

(14) Ver Carlton e Perloff (2000) para maiores detalhes sobre o tema. 
apenas os efeitos da operação sobre o total do excedente econômico ("custo social do monopólio"), mas também os efeitos sobre o excedente do consumidor (aumento de preços). Nesse sentido, o modelo 'padrão de preço' se aproximaria mais do objetivo traçado pela lei. Embora não garanta que os benefícios sejam distribuídos eqüitativamente entre consumidores e empresas, pelo menos impede que os consumidores sejam penalizados com aumentos de preços. O Guia (2001), por sua vez, exige apenas que os efeitos líquidos da operação sejam não negativos, sem apontar critérios de eqüidade, como requer o modelo de Willianson. ${ }^{15}$

\section{Análise da atuação do CADE entre 1994 e 2004}

A teoria antitruste apresentada acima será utilizada para a avaliação dos casos julgados do CADE. Como observado, a preocupação estruturalista relacionada com a concentração de mercado foi combinada com a análise das eficiências econômicas, que busca contrabalançar os efeitos negativos à concorrência de atos e condutas com seus possíveis benefícios de redução de custos.

\subsection{Metodologia}

Segundo WILLIG (1991), até 1982, o procedimento das autoridades antitruste em todo o mundo era bastante discricionário, valendo-se basicamente de valores de participação de mercado antes do ato ou da conduta e muito pouco preciso na forma de delimitação do mercado relevante. Somente com a publicação do Guidelines (1982) é que um conjunto de procedimentos destinados a medir o aumento de poder de mercado começou a ser utilizado de forma generalizada pelas cortes dos EUA. E mais, foi somente a partir da década de 1990 que os instrumentais econômicos passaram a ser usados para facilitar a aplicação, por intermédio do roteiro de análise, da teoria antitruste (Oliveira; Rodas, 2004). É nesse contexto que se coloca a questão se a teoria antitruste está sendo consistentemente aplicada pelo órgão de defesa da concorrência brasileiro.

Para respondê-la, é preciso avaliar como o CADE julgou, por meio do roteiro de análise antitruste, os atos e as condutas que deram ensejo a processos no período de julho de 1994 a dezembro de 2004. As decisões do CADE são proferidas por um colegiado composto por um presidente e seis conselheiros. Para cada processo, um conselheiro é escolhido, através de sorteio, para fazer o relatório sobre o caso. Esse relatório utiliza como referência, total ou parcialmente,

(15) A Portaria (Guia, 2001) não tem validade maior do que a Lei (8.884/1994). Esse é o entendimento recente do CADE para os julgados com cálculo de excedente econômico líquido, como será visto mais adiante. 
os pareceres da SEAE, SDE, da Procuradoria do CADE e do Ministério Público, quando existentes, e demais pareceres externos, quando contratados pelas partes. O conselheiro-relator justifica argumentativamente o seu voto, que poderá ser acatado ou não pelos outros conselheiros. É esse voto, e seu respectivo relatório, que usamos como referência para o estudo a ser apresentado. ${ }^{16}$

Os votos escolhidos foram retirados dos relatórios anuais do CADE de 1996 a 2003, que contêm todos os processos referentes a atos de concentração e condutas competitivas julgados no ano de referência. Os votos de 1994, 1995 e 2004 foram recolhidos na própria autarquia, ou, quando possível, no site do CADE na internet (www.cade.gov.br).

Este trabalho restringiu-se também aos casos que tiveram julgamento de mérito e utilização parcial ou total do roteiro de avaliação de atos de concentração ou condutas anticompetitivas. O julgamento de mérito é um filtro que permite a análise dos casos que realmente poderiam acarretar impacto(s) no(s) mercado(s) relevante(s), gerando possíveis efeitos econômicos. Dessa forma excluíram-se os processos e as consultas arquivados e/ou extintos sem julgamento de mérito, e aqueles extintos e/ou arquivados por despacho referendado, entre outros (embargos à declaração, recursos e consultas). Além disso, cabe salientar que o ano considerado é o do julgamento e não o da instauração do processo.

Já a necessidade de julgados com análise segundo o roteiro básico proposto pela teoria antitruste foi outro importante filtro para este trabalho, pois somente é possível avaliar a consistência teórica e empírica do CADE estudando aqueles casos que sigam, mesmo que sem uma seqüência rígida, as etapas básicas da análise antitruste. Excluem-se, assim, todos os julgados que não geram a necessidade de delimitação do mercado relevante e, por conseguinte, a avaliação da possibilidade de exercício de poder de mercado e o cômputo das eficiências líquidas, como as reorganizações societárias.

\subsection{Casos selecionados}

Entre os anos de 1994 e 2004, o CADE julgou 4.130 casos, sendo 3.200 atos de concentração e 930 processos administrativos referentes às condutas anticompetitivas (Gama, 2005b). Neste trabalho, no entanto, seguindo a metodologia exposta acima, foram analisados 330 casos.

(16) Quando feita a devida referência aos pareceres mencionados, analisamos, além do voto e relatório, tais pareceres. Caso o voto do conselheiro-relator tenha sido vencido, utilizamos também o texto do voto e relatório condutor do resultado. 
Tabela 1

Casos analisados

\begin{tabular}{l|c|c}
\hline Tipos & Número de casos & $\%$ \\
\hline Atos de Concentração & 242 & 73,3 \\
\hline Processos Administrativos & 88 & 26,7 \\
\hline Total & 330 & 100 \\
\hline Fonte: Elaboração dos autores &
\end{tabular}

Os resultados obtidos com a análise dos casos julgados escolhidos serão distribuídos de acordo com o roteiro de avaliação exposto no item anterior. Como visto, a estrutura recomendada pela teoria antitruste (roteiro de avaliação) implica os seguintes passos na análise de um ato de concentração ou de uma conduta anticompetitiva: (i) a delimitação do mercado relevante; (ii) a análise das condições de exercício de poder de mercado; (iii) o exame das eficiências geradas pela operação.

\section{Resultados da atuação do CADE entre 1994 e 2004}

Da análise feita sobre a consistência teórica dos julgados do CADE, a primeira impressão é, sem dúvida, a heterogeneidade da aplicação da teoria antitruste. Os casos analisados são muito díspares quanto à aplicação da teoria antitruste e a procedimentos de análise-padrão, pois, em apenas alguns casos, essa análise abrange todos os pontos propostos pela teoria. Para ilustrar esse argumento, observou-se que o emprego de testes sugeridos para a determinação da substituibilidade da demanda foi feito em apenas $14 \%$ dos casos em que a substituibilidade foi analisada, e o emprego de método quantitativo para o cálculo da eficiência econômica líquida, em apenas $5 \%$ dos julgados com alegação de eficiência econômica. A Tabela 2 mostra o panorama dos resultados encontrados.

Tabela 2

Síntese dos resultados

\begin{tabular}{l|c|r}
\hline & Número de casos & \multicolumn{1}{c}{$\%$} \\
\hline 1. Analisados & 330 & 100 \\
\hline 1.1 Substituibilidade da demanda & 205 & 62 (de 330) \\
\hline 1.1.1 Emprego de teste na dimensão produto & 29 & 14 (de 205) \\
\hline 1.2 Substituibilidade da oferta & 154 & 47 (de 330) \\
\hline 2. Concentração do mercado & 189 & 57 (de 330) e 100 \\
\hline 2.2 Análise da viabilidade da importação & 63 & 33 (de 189) \\
\hline 2.3 Análise das barreiras à entrada & 114 & $60($ de 189) \\
\hline 2.4 Eficiências alegadas & 98 & $52($ de 189) \\
\hline 2.4.1 Emprego de método quantitativo & 5 & $5($ de 98) \\
\hline
\end{tabular}

Fonte: Elaboração dos autores. 
Dos 330 casos analisados, na delimitação de mercado relevante, somente em $62 \%$ destes foi analisada a substituibilidade da demanda e em $47 \%$, a da oferta. E dentre os casos que analisaram a substituibilidade da demanda para delimitar o mercado relevante do ponto de vista do consumo (dimensão do produto e geográfica), somente em $14 \%$ houve o emprego de algum dos testes indicados pela teoria antitruste. Já em relação à concentração de mercado, 189 casos $(57 \%$ dos 330 casos) geraram a possibilidade de exercício de poder de mercado. Considerando agora esses 189 casos como o total, a análise da viabilidade da importação foi feita em 33\% dos casos e a análise das barreiras à entrada em $60 \%$. As eficiências foram argüidas em 98 julgados (52\%), mas somente em 5\% destes houve o emprego de método quantitativo para cômputo da eficiência econômica líquida.

\subsection{Mercado relevante}

A importância do mercado relevante reside no fato de que sua definição preliminar condiciona os resultados da etapas seguintes de avaliação do poder de mercado. Se a escolha da definição recair em mercados relevantes muito pequenos, serão constatadas participações relativamente maiores e, portanto, será detectado maior poder de mercado do que o efetivamente existente. Como consequiência, a política antitruste será mais severa do que o desejável; e o inverso ocorre caso o mercado relevante seja muito amplo. Para que essa delimitação seja correta é necessário considerar tanto a substituibilidade da demanda como a da oferta, uma análise realizada em poucos casos analisados.

\subsubsection{Substitutibilidade da demanda}

A Tabela 2 mostra que em $62 \%$ dos casos houve a análise da substituibilidade da demanda nas dimensões produto e geográfica, não importando se outros produtos ou regiões foram ou não incorporados ao mercado relevante. Isto é, em 205 casos houve uma análise dessa substituibilidade. A substituibilidade da demanda é condição indispensável para definir o(s) produto(s) e a(s) região (ões) relevante(s). Seu cálculo, através de algum instrumental econômico, é imprescindível.

Mas a Tabela 3 mostra que a substituição do consumo é na sua quase totalidade $(86 \%)$ considerada sem nenhuma técnica formal. Os testes realizados, mas em muito poucos casos, estavam relacionados basicamente à elasticidade (9\%), tanto a elasticidade-preço cruzada dos produtos, quando havia substitutos, quanto à elasticidade-preço da demanda, na inexistência deles. $\mathrm{O}$ TMH foi realizado em apenas $3 \%$ dos julgados analisados. Isso significa que, quando a 
substituibilidade da demanda é considerada, a análise é feita, muitas vezes, sem o rigor teórico necessário, isto é, sem a utilização de algum instrumental econômico recomendado pela teoria antitruste tradicional (os testes sugeridos para calcular a substituibilidade do produto considerado).

Tabela 3

Substituibilidade da demanda - Testes

\begin{tabular}{l|c|c}
\hline Utilizou Testes? & Número de casos & $\%$ \\
\hline Elasticidades da demanda & 19 & 9,2 \\
\hline Correlação temporal de preços & 4 & 2,0 \\
\hline Teste do monopolista hipotético & 6 & 2,9 \\
\hline Nenhum & 176 & 85,9 \\
\hline Total & 205 & 100 \\
\hline
\end{tabular}

Fonte: Elaboração dos autores.

No caso de cálculos para a elasticidade-preço da demanda destacou-se o julgado envolvendo o mercado relevante de cimento (concentrações verticais, como o AC de n. 08012.000345/00-55), no qual se concluiu que esse produto não tem substitutos próximos, já que a elasticidade para o cimento foi definida no intervalo de $(0,25 ; 0,35] .{ }^{17} \mathrm{O}$ produto relevante então seria o cimento apenas, restringindo a delimitação sugerida pelas empresas requerentes (cimento e concreto) e aumentando o poder de mercado das firmas envolvidas

Em alguns casos, como no ato envolvendo as empresas Warner-Lambert (AC n. 08012.012223/99-60), para determinar o mercado relevante de produto houve uma extensa discussão sobre a substituibilidade na demanda para produtos diferenciados. Para o relator, na falta de estudos econométricos mais abalizados, a solução seria a definição de um mercado relevante de produto mais restrita, haja vista que o mais importante, em casos de produtos diferenciados, não são os limites dos mercados formalmente definidos, mas a identificação da concorrência localizada. ${ }^{18}$ Adotou, assim, o mercado de gomas de mascar como o mercado relevante de produto, e não confeitos em geral, como queriam as representadas que, para tanto, calcularam as elasticidades-preço da demanda e cruzada para vários confeitos à base de açúcar.

No caso Nestlé/Garoto (AC n. 08012.001697/02-89), a questão da substituibilidade do produto foi extremamente relevante para delimitação do mercado como o de chocolates sob todas as formas. Para o relator, embora as elasticidades obtidas pelas requerentes (Nestlé/Garoto) fossem suspeitas devido às

(17) A estimação para a elasticidade foi feita através do método dos mínimos quadrados ordinários.

(18) O conceito de concorrência localizada é resultado da aplicação dos modelos de concorrência espacial (espaço no sentido das características dos produtos) desenvolvidos a partir do estudo clássico de Hotelling (1929) e surgiu nas discussões do caso Kellogg nos EUA em 1972. 
limitações do modelo PEM $^{19}$ utilizado nos principais trabalhos levados aos autos, os resultados puderam ser cotejados com os resultados obtidos por outros estudos e métodos (levados aos autos por partes interessadas, como a Lacta/Kraft), inclusive de análises qualitativas, de modo a estimar o comportamento das variáveis investigadas. A conclusão foi que os diferentes tipos e formatos de chocolates (tabletes, bombons, snacks e candy bars) das diferentes marcas (Nestlé, Garoto e Lacta) são substitutos entre si. Devem, portanto, ser incluídos num mesmo mercado relevante, segundo o critério do monopolista hipotético, dada a impossibilidade de serem praticadas elevações de preços superiores a $5 \%$, em um ou mais desses segmentos, sem perda de vendas e lucratividade para outro segmento com preços estáveis. Este caso consistiu em um exemplo da utilização da análise econômica para a delimitação do mercado relevante em um julgado do CADE. Houve a avaliação de todos os estudos levados aos autos, mas não a adoção de algum em específico de forma arbitrária, embora a instituição não tenha produzido internamente seus próprios resultados.

Já a aplicação da teoria antitruste para a delimitação geográfica do mercado relevante, principalmente quando regional, é consagrada pela utilização de versões do modelo de cidade linear de Hotelling (1929) aliado ao conceito por trás do TMH (percentual de aumento dos preços permitido para que um suposto monopolista atuasse no mercado). Alguns casos exemplificam essa aplicação. $\mathrm{Na}$ criação da AmBev (AC 08012.005846/99-12), a relatora definiu os mercados relevantes regionais com base nos custos de transporte incorridos nos deslocamentos do produto entre as fábricas e os centros de distribuição (frete do carreto). A partir de informações das requerentes relativas às variações dos custos de transporte de cerveja para diferentes distâncias, inferiu-se que na entrega do produto em localidades situadas a distâncias superiores a 400/500 km da fábrica (dependendo da localização original), a elevação no custo total provocada pelo custo do frete seria superior a $10 \%$, o que tornaria inviável a sua comercialização mesmo diante de um aumento de preços dos atuais ofertantes nesse mesmo percentual. Contudo, não houve um estudo interno ao SBDC sobre a delimitação do mercado que pudesse se contrapor às informações enviadas pelas requerentes.

\subsubsection{Substitutibilidade da oferta}

A elasticidade da oferta exige, para delimitação do mercado, a identificação daqueles grupos de vendedores relevantes, isto é, todos os produtores efetivos e ofertantes potenciais, de produtos que sejam seus substitutos na

(19) A metodologia do Price Elasticity Model (PEM) é estruturada de modo a identificar as mudanças nas participações de mercado resultantes de variações nos preços dos produtos e não da variação no volume total de mercado ou segmento de mercado analisado. Suas limitações recaem na presunção de igualdade de conhecimento, na distribuição e espaço nos locais de compra para todos os produtos, além da inexistência de restrição orçamentária. 
produção. Assim, deveriam ser considerados como participantes do mercado também os produtores potenciais de curto prazo, isto é, empresas que não produzem atualmente, mas que podem passar a produzir em resposta a um 'pequeno, porém significativo e não transitório aumento' dos preços (Guia, 2001).

A elasticidade da oferta foi analisada em $47 \%$ dos casos, mas em nenhum deles houve o exercício de definir potenciais ofertantes que não incorreriam em custos irrecuperáveis para iniciar a produção (Tabela 2). Como exemplo, podemos citar a compra pela Belgo Mineira da Mendes Júnior (AC n. 44/95), em que a delimitação do mercado relevante foi considerada mais abrangente, pois no setor de aços longos há um considerável grau de substituibilidade devido à elevada flexibilidade produtiva das empresas instaladas. $\mathrm{O}$ mercado passou a ser definido como o de aços longos comuns, nas linhas vergalhão, laminados e trefilados.

\subsection{Exercício do poder de mercado}

Uma vez delimitado o mercado relevante, a utilização de medidas de concentração de mercado, a análise da viabilidade da competição externa e a avaliação do nível das barreiras à entrada são os principais instrumentos de inferência da extensão do poder de mercado.

\subsubsection{Concentração e índices}

O número de casos que tiveram seu mercado concentrado ou que ocorreram em mercados previamente concentrados é significativo (57\% dos casos). No entanto, mesmo não havendo mudança nas participações de mercado entre as empresas, devido à entrada via aquisição, fusão ou associação pode haver mudança considerável na dinâmica concorrencial.

Para verificar como a concentração de mercado é mensurada pelo CADE, foram analisados todos os casos em que houve concentração efetiva (189 casos ou $58 \%$ do total), que necessariamente teriam que referenciar algum índice de concentração ou, no mínimo, a participação de mercado. A análise mostra o emprego regular da participação de mercado em detrimento dos índices $\mathrm{HH}$ e $\mathrm{Ci}$, que carregam maiores informações sobre a estrutura de mercado.

Tabela 4

Índices de concentração

\begin{tabular}{l|c|c}
\hline Índices Utilizados & Número de casos & $\%$ \\
\hline $\mathrm{HH}$ & 31 & 16,4 \\
\hline $\mathrm{Ci}$ & 28 & 14,9 \\
\hline $\mathrm{HH}$ e Ci & 9 & 4,7 \\
\hline Participação & 126 & 64,0 \\
\hline Total & 189 & 100 \\
\hline
\end{tabular}

Fonte: Elaboração dos autores. 


\subsubsection{Importação}

A importação é um importante fator de contestabilidade, isto é, é inibidor do abuso de poder de mercado. Deve-se considerar a possibilidade de que as importações aumentem, em quantidade e prazo razoáveis. Segundo este estudo, no entanto, a análise da importação é relegada a um segundo plano pelo CADE, sendo realizada em apenas $33 \%$ (Tabela 2) dos casos em que houve concentração (189 julgados). Esses geralmente são casos em que, notoriamente, a importação seria relevante pelo fluxo comercial internacional mais intenso.

As suposições feitas pelos relatores nos casos em que a importação foi analisada, com raras exceções, não tiveram como contrapartida uma avaliação de preços FOB e dos custos de internação do produto (frete marítimo, seguro, imposto de importação e despesas de desembaraço aduaneiro), recomendada pela análise antitruste. Na sua maioria, o parâmetro de comparação utilizado entre preços interno e externo foi apenas a alíquota de importação, procedimento superficial para avaliação do comércio exterior neste contexto.

Uma exceção foi o ato de concentração n. 12/94 (compra pela Rhodia da Sinasa), que trouxe aos autos uma análise mais detalhada da viabilidade da importação para o mercado de fibras sintéticas. Os preços médios de venda no mercado nacional eram de US\$ 1,55/kg para as fibras de poliéster e US\$2,05 para as fibras acrílicas. Por sua vez, os preços FOB no mercado internacional eram, respectivamente, US\$1,16/kg e US\$ 1,73 . O custo total da internação estava na faixa de US\$ 1,56/kg para poliéster e de US\$ 2,61 para fibra acrílica. Assim, segundo o conselheiro-relator, a importação, que já estava ocorrendo, inibiria um possível aumento de preços.

\subsection{Barreiras à entrada}

Quanto às barreiras à entrada, é imprescindível incluir na definição de mercado relevante os ofertantes potenciais (uncommitted entrants), para que na etapa de avaliação da entrada sejam consideradas apenas aquelas firmas que agregarão (ou terão capacidade de agregar) capacidade produtiva ao mercado (committed entrants). Uma rigorosa avaliação das barreiras é necessária para se concluir sobre a efetividade do exercício de poder de mercado, pois nenhum ato ou conduta realizado em mercados relevantes onde as barreiras à entrada são baixas deve gerar maiores preocupações das autoridades antitruste. No entanto, para que uma entrada seja considerada possível e, portanto, o mercado seja considerado contestável, é necessária a satisfação conjunta das condições de temporalidade, de probabilidade e de suficiência de entrada. Muito freqüentemente a entrada é 
considerada livre ou não sem que essas condições para entrada sejam verificadas conjuntamente.

O resultado da pesquisa mostra que a análise das barreiras à entrada foi feita em somente $60 \%$ dos casos em que era necessária (189 casos com concentração). Foram considerados como analisados aqueles casos em que apenas houve menção à existência ou não das barreiras. De fato, dos 330 casos analisados, somente o ato de concentração envolvendo a Abbott (AC de n. 08012.000210/0241) trouxe aos autos a análise conjunta das três condições de entrada.

Nele, o conselheiro-relator considerou a entrada no setor de kits e bandejas cirúrgicas livre, pois uma empresa poderia iniciar sua operação no mercado em questão via importação (forma mais fácil) somente com a obtenção dos registros junto ao Ministério da Saúde e a montagem de uma equipe de vendas que faria a divulgação dos kits e bandejas aos médicos e hospitais. Dessa forma, uma vez obtidos os registros necessários (o que exige aproximadamente seis meses ao custo de $\mathrm{R} \$ 13$ mil por produto) e formada e treinada uma equipe de vendas (três meses com custo de $\mathrm{R} \$ 2,5$ milhões), a empresa estaria apta a operar no mercado brasileiro após nove meses e R\$ 2,6 milhões gastos. Isso indicou a probabilidade de a entrada ser 'tempestiva', isto é, realizável em nove meses e, dado o faturamento anual mínimo para que uma empresa entrasse no mercado de forma economicamente viável de $\mathrm{R} \$ 350$ mil (10\% do faturamento do mercado), também 'provável' (lucrativa). Por fim, partindo da hipótese de que as firmas identificadas no exterior têm capacidade financeira de entrar no mercado nacional de modo a gerar uma competição efetiva, o conselheiro-relator considerou que a entrada desses concorrentes potenciais também seria 'suficiente' para garantir a competição no mercado relevante previamente definido.

\subsection{Eficiências econômicas}

O cálculo das eficiências econômicas líquidas deve ser feito nas operações em que há possibilidade de exercício de poder de mercado, mesmo quando este pôde ser mitigado pela importação e baixo nível de barreiras à entrada. Aqui se buscou saber se as eficiências foram alegadas ou não. Em caso positivo, foi especificado o tipo de eficiência alegada para, então, analisar o cômputo do resultado líquido entre os efeitos benéficos e anticompetitivos do ato de concentração ou prática restritiva.

As eficiências foram alegadas em 98 casos ou 52\% daqueles 189 com possibilidade de exercício de poder de mercado (Tabela 3). A alegação da eficiência, entretanto, não significa que elas foram aceitas. Geralmente o CADE considera como eficiências específicas da concentração aquelas cuja magnitude e possibilidade de ocorrência possam ser verificadas por meios razoáveis e para as 
quais as causas (como) e o momento em que serão obtidas (quando) estejam especificados.

A Tabela 5 abaixo traz os resultados sobre a alegação das eficiências. Caso elas tenham sido alegadas, avaliou-se se foram devidamente tipificadas. As eficiências econômicas reconhecidas pela teoria antitruste podem ser de dois tipos: as produtivas e as referentes aos custos de transação. Se não forem produtivas nem referentes aos custos de transação, as eficiências foram tipificadas como outras. Por fim, elas podem não ter sido alegadas.

Tabela 5

Eficiências alegadas

\begin{tabular}{l|c|c}
\hline Tipos & Número de casos & $\%$ \\
\hline Eficiência produtiva & 56 & 29,6 \\
\hline Redução do custo de transação & 20 & 10,6 \\
\hline Outras eficiências & 22 & 11,7 \\
\hline Total com pleito de eficiências & 98 & 51,9 \\
\hline Total sem pleito de eficiências & 91 & 48,1 \\
\hline Total & 189 & 100 \\
\hline
\end{tabular}

Fonte: Elaboração dos autores.

Das eficiências alegadas, as produtivas compõem o maior grupo. Isso talvez seja decorrência de uma facilidade relativamente maior em se verificar e quantificar os ganhos de produtividade, em parte porque as informações necessárias são de conhecimento das empresas envolvidas. O que propõe a teoria antitruste é considerar um ganho de eficiência como um ganho de produtividade, resultando na redução de custos unitários. Por isso, a aceitação das eficiências resultantes da economia de custos de transação foi restringida a casos específicos, sobretudo àqueles que envolvem atos ou condutas de empresas verticalizadas.

As eficiências econômicas alegadas podem ser submetidas, se quantificáveis e aceitas, a um dos dois modelos (o 'padrão de preço' e o critério de Willianson) que buscam mensurar o efeito líquido da operação ou conduta. No entanto, esses modelos foram empregados em apenas cinco casos. Por fim, cabe dizer que o modelo de 'padrão de preço' se aproxima mais do objetivo traçado pela lei, enquanto o Guia (2001) exige apenas que os efeitos líquidos da operação sejam não negativos, sem apontar critérios de eqüidade. A jurisprudência incipiente do CADE sobre o assunto indica uma tendência pelo uso do modelo de preço-padrão, pois esse foi o modelo adotado pelos conselheiros nos casos da AmBev (AC de n. 08012.005846/99-12) e Nestlé/Garoto (AC de n. 08012.001697/ 02-89). Em ambos os casos, as eficiências alegadas, segundo seus relatores, não compensariam as perdas para os consumidores representadas pelo provável 
aumento de preços dos produtos relevantes. ${ }^{20}$ Sem dúvida, segundo o modelo 'padrão de preço', essas operações precisariam gerar eficiências elevadas e que pudessem ser posteriormente distribuídas eqüitativamente entre as empresas e os consumidores.

\section{Práxis antitruste no Brasil}

A teoria de Organização Industrial gerou instrumentos analíticos capazes de fornecer uma orientação para o exame antitruste de atos de concentração e práticas restritivas por parte das autoridades responsáveis pela defesa da concorrência. No entanto, esse exame se depara com diversas dificuldades analíticas, sobretudo as referentes à operacionalidade de certos aspectos da teoria, tais como a definição do mercado relevante via utilização dos testes econômicos para inferir a substituibilidade da demanda, e a aferição quantitativa do trade-off entre eficiência e poder de mercado. Tais dificuldades originam-se da formulação teórica desses temas em economia. Nesse tema, mais que em outros, a indeterminação econômica no plano conceitual conspira contra a premência jurídica por referências e parâmetros determinados. Assim, é preciso admitir que não se dispõe, na análise antitruste, de um critério normativo único e inteiramente satisfatório para avaliar e ponderar benefícios e custos sociais de atos de concentração e condutas anticompetitivas.

\subsection{Delimitação mercado relevante}

Quanto à delimitação do mercado relevante na substituibilidade do consumo, o que o resultado do trabalho mostrou foi, sobretudo, uma dificuldade em realizar os testes indicados pela teoria antitruste. O problema provavelmente consiste na falta de praticidade da aplicação desses testes diante da frágil base informacional (ausência de dados setoriais consistentes, séries de tempo para preços de produtos e estudos setoriais defasados) e da dificuldade em se obterem estimativas do comportamento dos consumidores diante de uma elevação nos preços do produto em questão (cálculo das elasticidades).

Já em relação à substituibilidade da oferta, de modo geral o que se pôde perceber foi a existência de uma separação entre a análise das condições de demanda, tratadas na definição de mercado relevante, e as de oferta, tratadas no contexto das condições de entrada no mercado. Essa separação não teria maiores

(20) No caso AmBev, as eficiências aceitas representariam uma redução máxima nos custos de 6,9\%, bem inferior aos $14,1 \%$ necessários para compensar o provável aumento de preços; no caso Nestlé/Garoto, a redução de custos aceita estaria no intervalo de $1,47 \%$ a $2,16 \%$, e não no intervalo de $11 \%$ a $12 \%$ requerido pelo modelo. 
consequiências não fosse a importância estratégica assumida pelo conceito de mercado relevante na aplicação da teoria antitruste.

\subsection{Possibilidade de exercício de poder de mercado}

A avaliação da possibilidade de exercício de poder de mercado tem início com uma análise da concentração de mercado, inclusive com sua mensuração. No entanto, como já enfatizado, a concentração não é pressuposta para o exercício de poder de mercado e, por isso, não deveria ser um ponto focal na análise antitruste como o é atualmente. O grau de concentração de um mercado, por si só, não deveria ser levado em consideração pelo CADE como condição necessária e/ou suficiente para que se considere danosa à concorrência uma determinada operação ou conduta anticompetitiva. A concentração, medida através dos índices $\mathrm{HH}, \mathrm{Ci}$ ou pela simples participação de mercado, serve apenas como um indicativo para a análise antitruste ao lado de outros elementos utilizados.

Outra questão importante a ser ressaltada é que não devem ser utilizados, a priori, parâmetros para concentração importados de outros países, como os 1.800 pontos do HHI (estadunidense), ou os $75 \%$ do C4 (europeu), dadas as peculiaridades da economia brasileira. Independentemente do indicador, a análise de impacto estrutural em economias como a brasileira deve levar em conta o tamanho mais reduzido de seus mercados, sobretudo quando se busca transplantar as faixas de referência do HHI utilizadas pelos órgãos dos EUA, ou do C4 utilizadas pela União Européia, economias maiores e estruturalmente diferentes da brasileira. Seria prudente, portanto, o estabelecimento de critérios próprios para definição dos parâmetros críticos de concentração no mercado brasileiro.

Além disso, é fundamental observar que não há como se estimar de maneira objetiva o impacto de uma concentração sobre a concorrência - isto é, sobre o poder de mercado. Isso dependerá de um grande número de atributos da estrutura do mercado, das características, portanto, de cada mercado e da forma como neles se manifesta a competição. Assim, percebe-se uma superestimativa da importância que se atribui ao grau de concentração do mercado como indicador supostamente decisivo para avaliar o impacto de uma operação sobre a concorrência, como era de esperar de uma teoria econômica baseada no modelo ECD.

A avaliação do exercício do poder de mercado deveria não se prender a uma análise quase que fundamental da concentração, mas considerar mais rigorosamente outros fatores de contestabilidade de mercado, como a importação e a probabilidade de entrada (e.g. as três condições de entrada), mesmo que estas sejam relativamente menos favoráveis do que em economias mais desenvolvidas, 
em virtude da restrição do comércio exterior, imperfeição dos mercados de capitais e limitações de infra-estrutura, entre outros fatores. Ainda é importante ressaltar as dificuldades para mensurar o nível das barreiras à entrada. Não existe um instrumental econômico ou informações que classifiquem o grau de bloqueio à entrada. Dessa maneira, é sempre exigido algum exercício de juízo por parte do investigador.

\subsection{Análise das eficiências econômicas}

Quanto à análise das eficiências, o que fica claro é a dificuldade encontrada para se quantificar o efeito líquido de um ato de concentração ou prática restritiva. Como a estimativa das reduções de custos é de inteira responsabilidade das partes envolvidas, e os dados sobre os preços podem ser de difícil obtenção, a aplicação dos modelos, devido, sobretudo, à necessidade de estimar resultados de mercado pós-fusão (redução de custo e aumento de preços), não é imediata. Uma solução parcial para esse problema seria a criação de equipes de técnicos e especializadas capazes de averiguar com maior conhecimento as informações técnicas enviadas pelas empresas. Tal dificuldade não passou despercebida por Willianson, que sugeriu o reconhecimento, a priori, de métodos de obtenção das economias de recursos (Viscusi et al., 1995). ${ }^{21}$

\section{Considerações finais}

Uma das maiores dificuldades impostas ao SBDC está relacionada à disponibilidade da informação. Por não possuir uma fonte de dados própria ou de outro órgão federal coligado, o SBDC fica impossibilitado de utilizar instrumentais econômicos imparciais para inferir considerações sobre o mercado em análise. Diante desse fato, a solução encontrada, sobretudo pelo CADE, foi a de utilizar, para diversos fins, dados provenientes de empresas privadas contratadas geralmente pela(s) empresa(s) envolvida(s) no ato ou prática restritiva e/ou realizar avaliações dos trabalhos econômicos levados aos autos. O problema desse procedimento é a dúvida permanente sobre a parcialidade das informações. Assim, apesar da necessidade da aplicação da teoria antitruste na tomada de decisão pelo órgão responsável pela defesa da concorrência no Brasil, é notória alguma dificuldade no emprego de certos instrumentos econômicos.

(21) Hoje o que tem uso freqüente nos EUA e na Europa, e também já está em estudo no Brasil (citou-se em um seminário realizado pelo CADE/SDE e Ipea em 2005 sobre defesa da concorrência), é a simulação de fusões para quantificar o efeito unilateral de um ato de concentração, que nada mais é do que o uso de um modelo de oligopólio e uma função de demanda para inferir o possível aumento de preços que a fusão irá ocasionar. 
A falta de informação, aliada à falta de operacionalidade de alguns conceitos-chave econômicos para a análise antitruste, levam à adoção de uma práxis de defesa da concorrência muitas vezes afastada da teoria econômica, mesmo dos seus procedimentos mais convencionais e menos complexos. Em suma, essa práxis significa uma aplicação da teoria antitruste pelos órgãos de defesa econômica de forma heterogênea e fragilizada.

A aplicação heterogênea e pouco rigorosa da teoria antitruste pelo órgão responsável pela defesa da concorrência no Brasil tem uma consequiência importante: a criação de uma jurisprudência antitruste nacional. A consolidação de uma jurisprudência é resultado de uma práxis antitruste, uma política específica que visa a prevenir colusões entre firmas e abusos de poder econômico. Assim, é necessário que a política antitruste se consolide no Brasil através da aplicação pelo SBDC, sobretudo pelo CADE, da teoria econômica e seus preceitos para avaliação de atos de concentração e práticas restritivas, a fim de se construir uma jurisprudência nacional e inserir o Brasil no rol de países industrializados capazes de promover uma efetiva, pública e balizada regulação econômica.

\section{Referências bibliográficas}

BAIN, J. S. Barriers to new competition, their character and consequences in manufacturing industries. Cambridge, Mass: Harvard University, 1956. 329p.

BONNER, R. A.; KRUEGER, R. The basics of antitrust policy: a review of ten nations and the European Communities. Washington, D.C.: World Bank, 1991. 127p. (World Bank Technical Paper, n. 160).

CARLTON, D. W.; PERLOFF, J. M. Modern industrial organization. 3. ed. Reading, Mass: Addison-Wesley, 2000. 780p.

FAGUNDES, J.; PONDÉ, J. Barreiras à entrada e defesa da concorrência. Revista de Economia Contemporânea, v. 1, n. 2, p. 61-89, jul./dez. 1997.

FISHER, A.; JOHNSON, F.; LANDE, R. Price effects of horizontal mergers. California Law Review, v. 77, n. 4, p. 777-827, Jul. 1989.

GAMA, M. Teoria e práxis da defesa da concorrência no Brasil. Dissertação (Mestrado em Economia)-Centro de Desenvolvimento e Planejamento Regional, Universidade Federal de Minas Gerais, Belo Horizonte, MG, 2005a

Teoria antitruste: fundamentos e estado da arte. In: ENCONTRO NACIONAL

DE ECONOMIA POLÍTICA, 10, Campinas. Anais... SEP, 2005b

GEROSKI, P. Competition policy and the structure-performance paradigm. In: DAVIES, S.; LYONS, B. (Ed.). Economics of industrial organization: surveys in economics. London: Longman, 1988. cap. 5, p. 166-191.

GUIDELINES. The Merger Guidelines. Department of Justice and Federal Trade Comission, 1982. 
GUIDELINES. The Horizontal Merger Guidelines. Department of Justice and Federal Trade Comission, 1997.

GUIA para Análise Econômica de Atos de Concentração Horizontal. In: BRASIL. Ministério da Fazenda, Secretaria de Acompanhamento Econômico. Portaria Conjunta SEAE/SDE n. 50, de 01 de agosto de 2001. Diário Oficial da União, n. 158-E, 17 ago. 2001, Seção 1, p.12-15. Disponível em: <http://www.fazenda.gov.br/seae>. Acesso em: 17 ago. 2004.

HARBERGER, A. Monopoly and resource allocation. American Economic Review, v. 44, n. 2, p.77-78, 1954.

HORIZONTAL MERGER GUIDELINES. In: United States. Department of Justice and Federal Trade Commission, Apr. 8, 1997.

HOTELLING, H. Stability in competition. Economic Journal, v. 39, p. 41-57, Mar. 1929.

HOVENKAMP, H. Antitrust. 2. ed. St. Paul (Minn): West Publ., 1994.

KUPFER, D.; HASENCLEVER, L. (Org.). Economia industrial: fundamentos teóricos e práticas no Brasil. Rio de Janeiro: Campus, 2002. 640p.

OLIVEIRA, G.; RODAS, J. Direito e economia da concorrência. São Paulo: Renovar, 2004.

POSNER, R. Antitrust law: an economic perspective. Chicago: University of Chicago, 1976. 262p.

POSSAS, M. L. Estruturas de mercado em oligopólio. São Paulo: Hucitec, 1985.

Os conceitos de mercado relevante e de poder de mercado no âmbito da defesa da concorrência. Revista do IBRAC, v. 3, n. 5, p. 10-35, 1996.

. (Org.). Ensaios sobre economia e direito da concorrência. São Paulo: Singular, 2002. 238p.

; FAGUNDES, J.; PONDÉ, J. Política antitruste: um enfoque schumpeteriano. In: ENCONTRO NACIONAL DE ECONOMIA, 23, 1995, Salvador. Anais... [São Paulo]: Anpec, 1995. v. 2, p. 270-289.

; FAGUNDES, J.; PONDÉ, J. Custos de transação e políticas de defesa da concorrência. Revista de Economia Contemporânea, n. 2, p. 115-135, jul./dez. 1997.

RESOLUÇÃO N. 20 do CADE. In: BRASIL. Ministério da Justiça, Conselho Administrativo de Defesa Econômica, CADE. Resolução n. 20, de 09 de junho de 1999. Diário Oficial da União, 28 jun. 1999. Disponível em: <http://www.cade.gov.br>. Acesso em: 20 ago. 2004.

SALGADO, L. H. A economia política da ação antitruste. São Paulo: Singular, 1997.

SCHERER, F. M.; ROSS, D. Industrial market structure and economic performance. 3. ed. Boston: Houghton Mifflin, 1990. 713p.

STIGLER, G. The Organization of Industry. R.D. Irwin, 1968. 328p. 
Marina Moreira da Gama / Ricardo Machado Ruiz

TIROLE, J. The theory of industrial organization. Cambridge, Mass.: MIT Press, 2002.

VISCUSI, W.; VERNON, J. E.; HARRINGTON, J. Economics of regulation and antitrust. Lexington, MA.: D.C. Heath and Company, 1995.

WILLIANSON, O. E. Economies as an antitrust defense: the welfare trade-offs. American Economic Review, v. 58, n. 1, p.18-36, Mar. 1968.

WILLIG, R. Mergers analysis, industrial organization theory and merger guidelines. Brookings Papers on Economic Activity, v. 1991, p. 281-312. 1991. 